\title{
DOR: O QUINTO SINAL VITAL
}

Fátima Aparecida Emm Faleiros Sousa ${ }^{1}$

Sousa FAEF. Dor: o quinto sinal vital. Rev Latino-am Enfermagem 2002 maio-junho; 10(3):446-7.

\begin{abstract}
A Agência Americana de Pesquisa e Qualidade em Saúde Pública e a Sociedade Americana de Dor descrevem a dor como o quinto sinal vital que deve sempre ser registrado ao mesmo tempo e no mesmo ambiente clínico em que também são avaliados os outros sinais vitais, quais sejam: temperatura, pulso, respiração e pressão arterial.

A Sociedade Americana para a Medicina de Emergência, em sua reunião anual realizada em 2001, também reconheceu a importância de se registrar e mensurar a percepção de dor tanto aguda quanto crônica. Em decorrência dessa ênfase na mensuração da dor, diferentes instituições de saúde têm, atualmente, recomendado que os clientes sejam questionados se estão sentindo dor no momento da admissão para tratamento e, também, durante a evolução clínica.
\end{abstract}

A dor pode ser definida como uma experiência subjetiva que pode estar associada a dano real ou potencial nos tecidos, podendo ser descrita tanto em termos desses danos quanto por ambas as características. Independente da aceitação dessa definição, a dor é considerada como uma experiência genuinamente subjetiva e pessoal. A percepção de dor é caracterizada como uma experiência multidimensional, diversificando-se na qualidade e na intensidade sensorial, sendo afetada por variáveis afetivo-motivacionais.

\section{POR QUE MENSURAR A DOR?}

Por ser uma experiência subjetiva, a dor não pode ser objetivamente determinada por instrumentos físicos que, usualmente, mensuram o peso corporal, a temperatura, a altura, a pressão sangüínea e o pulso. Em outras palavras, não existe um instrumento padrão que permita a um observador externo, objetivamente, mensurar essa experiência interna, complexa e pessoal.

A despeito dessas dificuldades intrínsecas, por que mensurar a dor? A mensuração da dor é extremamente importante no ambiente clínico, pois torna-se impossível manipular um problema dessa natureza sem ter uma medida sobre a qual basear o tratamento ou a conduta terapêutica. Sem tal medida, torna-se difícil determinar se um

\footnotetext{
${ }^{1}$ Professor Associado da Escola de Enfermagem de Ribeirão Preto, da Universidade de São Paulo, Centro Colaborador da OMS para o desenvolvimento da pesquisa em enfermagem, e-mail: faleiros@eerp.usp.br
} 
tratamento é necessário, se o prescrito é eficaz ou mesmo quando deve ser interrompido.

Com uma mensuração apropriada da dor torna-se possível determinar se os riscos de um dado tratamento superam os danos causados pelo problema clínico e, também, permite-se escolher qual é o melhor e o mais seguro entre diferentes tipos. Uma medida eficaz da dor possibilita examinar a sua natureza, as suas origens e os seus correlatos clínicos em função das características emocionais, motivacionais, cognitivas e de personalidade do cliente.

Algumas vezes, apenas medidas grosseiras, tais como "dor presente" ou "dor ausente", são necessárias para as intervenções clínicas; mas, para completamente entender o fenômeno e avaliar a eficácia dessas intervenções, necessitamos de medidas mais sofisticadas tanto da intensidade quanto das respostas afetivas associadas à dor.

\section{MENSURAÇÃO DA DOR}

Vários métodos têm sido utilizados para mensurar a percepção/sensação de dor. Alguns métodos consideram a dor como uma qualidade simples, única e unidimensional que varia apenas em intensidade, mas outros a consideram como uma experiência multidimensional composta também por fatores afetivo-emocionais.

Os instrumentos unidimensionais são designados para quantificar apenas a severidade ou a intensidade da dor e têm sido usados freqüentemente em hospitais e/ou clínicas para se obterem informações rápidas, não invasivas e válidas sobre a dor e a analgesia. Exemplos desses instrumentos são as escalas de categoria numérica/verbal e a escala analógico-visual que são freqüentemente empregadas em ambientes clínicos, por serem de aplicação fácil e rápida. Os instrumentos multidimensionais, de outro lado, são empregados para avaliar e mensurar as diferentes dimensões da dor a partir de diferentes indicadores de respostas e suas interações. As principais dimensões avaliadas são a sensorial, a afetiva e a avaliativa. Algumas escalas multidimensionais incluem indicadores fisiológicos, comportamentais, contextuais e, também, os auto-registros por parte do paciente. Exemplos desses instrumentos são a escala de descritores verbais diferenciais, o Questionário McGill de avaliação da dor e a teoria da detecção do sinal. Com essas escalas, tornase possível avaliar a dor em suas múltiplas dimensões, ou seja, os componentes sensoriais, afetivos e avaliativos que estão refletidos na linguagem usada para descrever a experiência dolorosa.

Em resumo, atualmente, a dor é considerada um sinal vital, tão importante quanto os outros e deve sempre ser avaliada num ambiente clínico, para se empreender um tratamento ou conduta terapêutica. A eficácia do tratamento e o seu seguimento dependem de uma avaliação e mensuração da dor confiável e válida. Dada essa ênfase na mensuração e na avaliação da dor, entendemos que todas as escolas médicas e de enfermagem, bem como as de áreas paramédicas correlatas, deveriam, urgentemente, implementar, em suas estruturas curriculares, disciplinas ou cursos com o propósito de ensinar e disseminar o uso desses instrumentos e/ou escalas de avaliação e mensuração da dor. 